\title{
Measurement of nonvolatile particle number size distribution
}

\section{G. I. Gkatzelis et al.}

Correspondence to: S. N. Pandis (spyros@ @ chemeng.upatras.gr)

The copyright of individual parts of the supplement might differ from the CC-BY 3.0 licence. 


\section{Thermodenuder description}

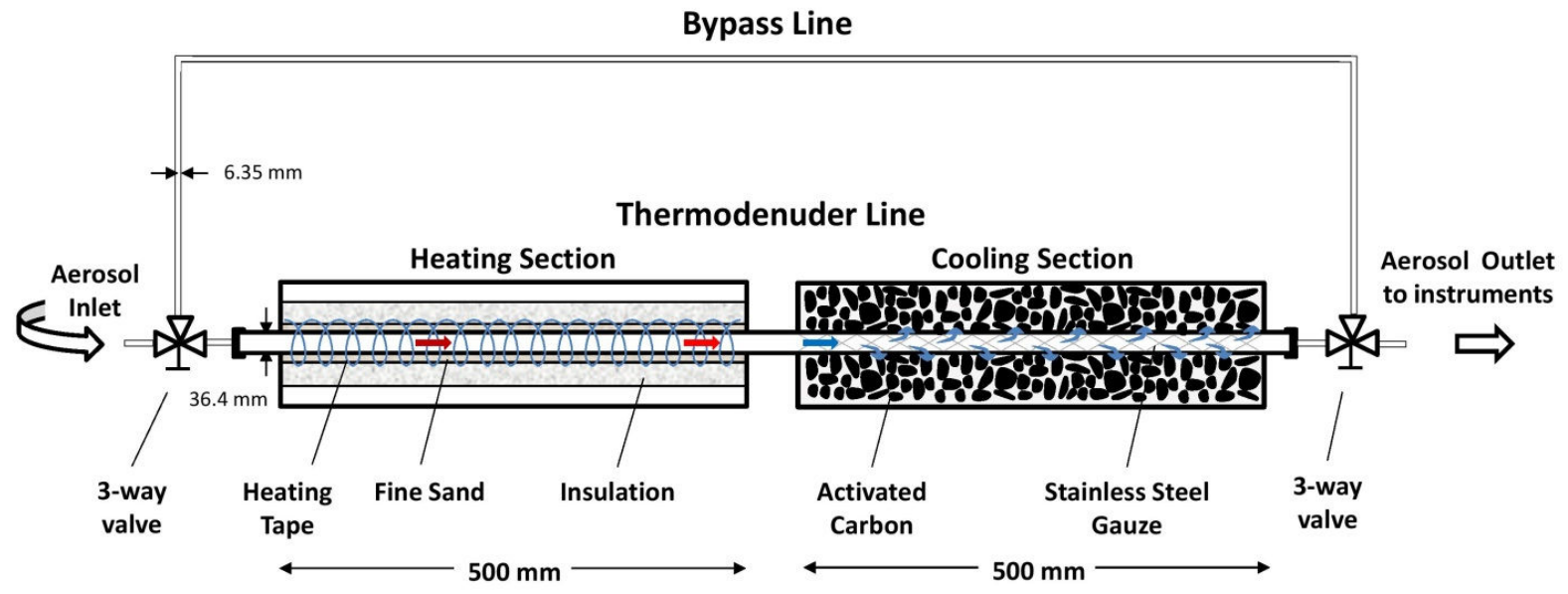

Figure S1: Schematic of the thermodenuder used in this study. 


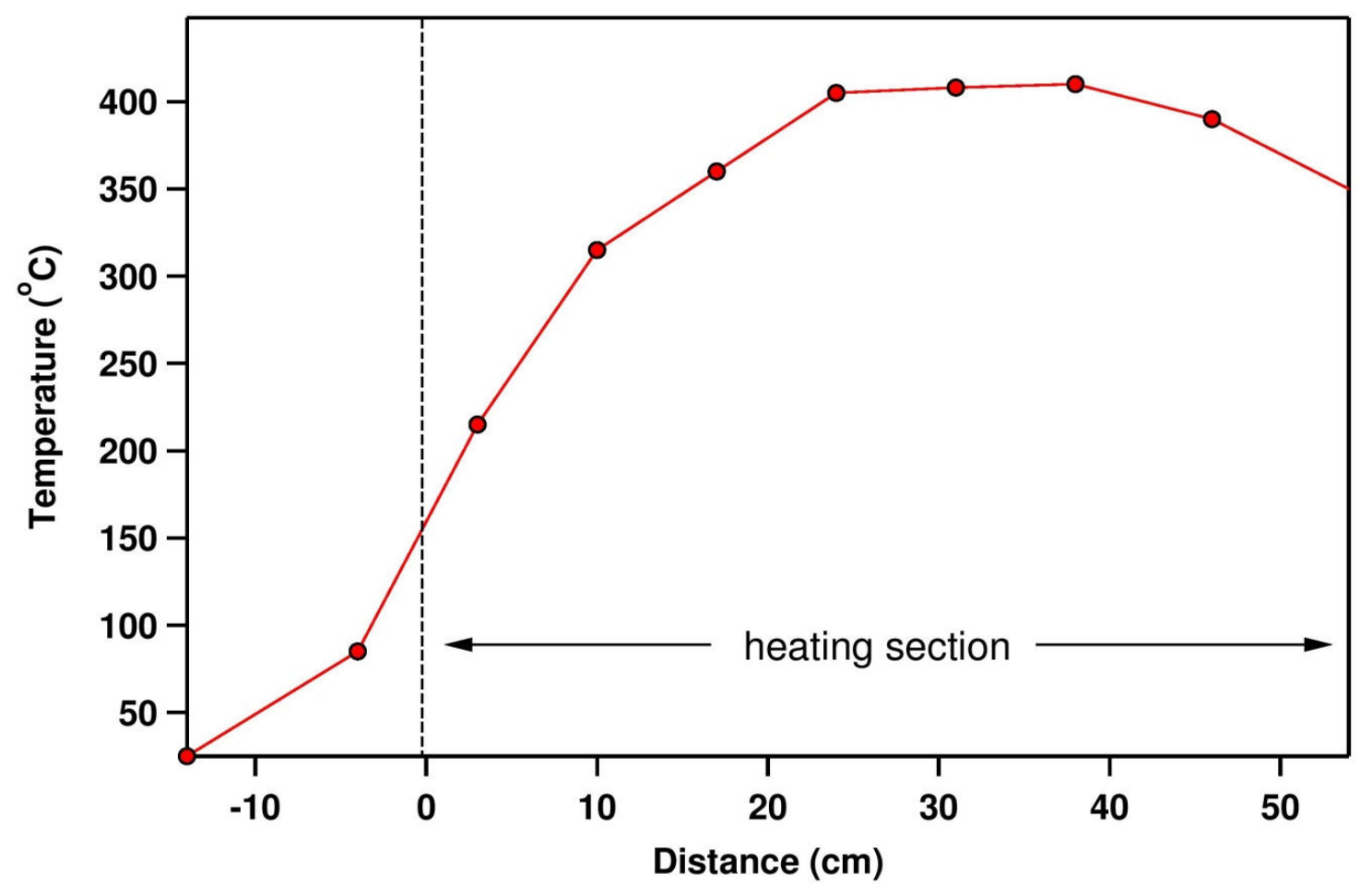

Figure S2: Temperature profile inside the heating section of the TD at the set temperature of 400 ${ }^{\circ} \mathrm{C}$ and a flow rate of $1 \mathrm{~L} \mathrm{~min}^{-1}$ as a function of position (distance from the entrance of the heating section). 


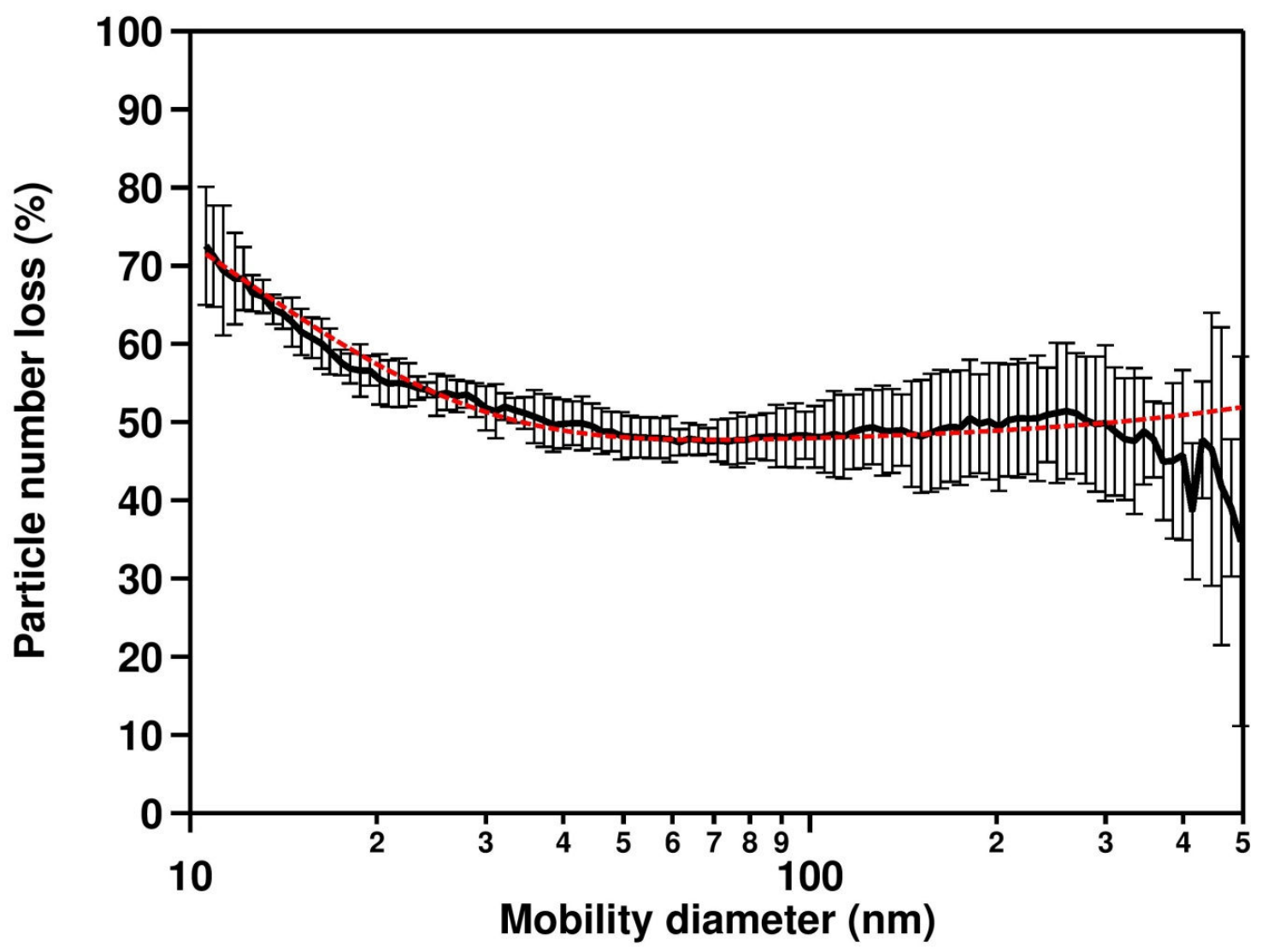

Figure S3: Average particle number loss at $400{ }^{\circ} \mathrm{C}$ based on 9 different experiments of $\mathrm{NaCl}$ aerosol generated with an atomizer, using a flow rate of. The fit function for wall losses is given from the red dash line. The precision $( \pm 2 \sigma)$ of the average loss correction is given by the vertical lines. Details are given in the text. 
2. Athens 2013 winter campaign

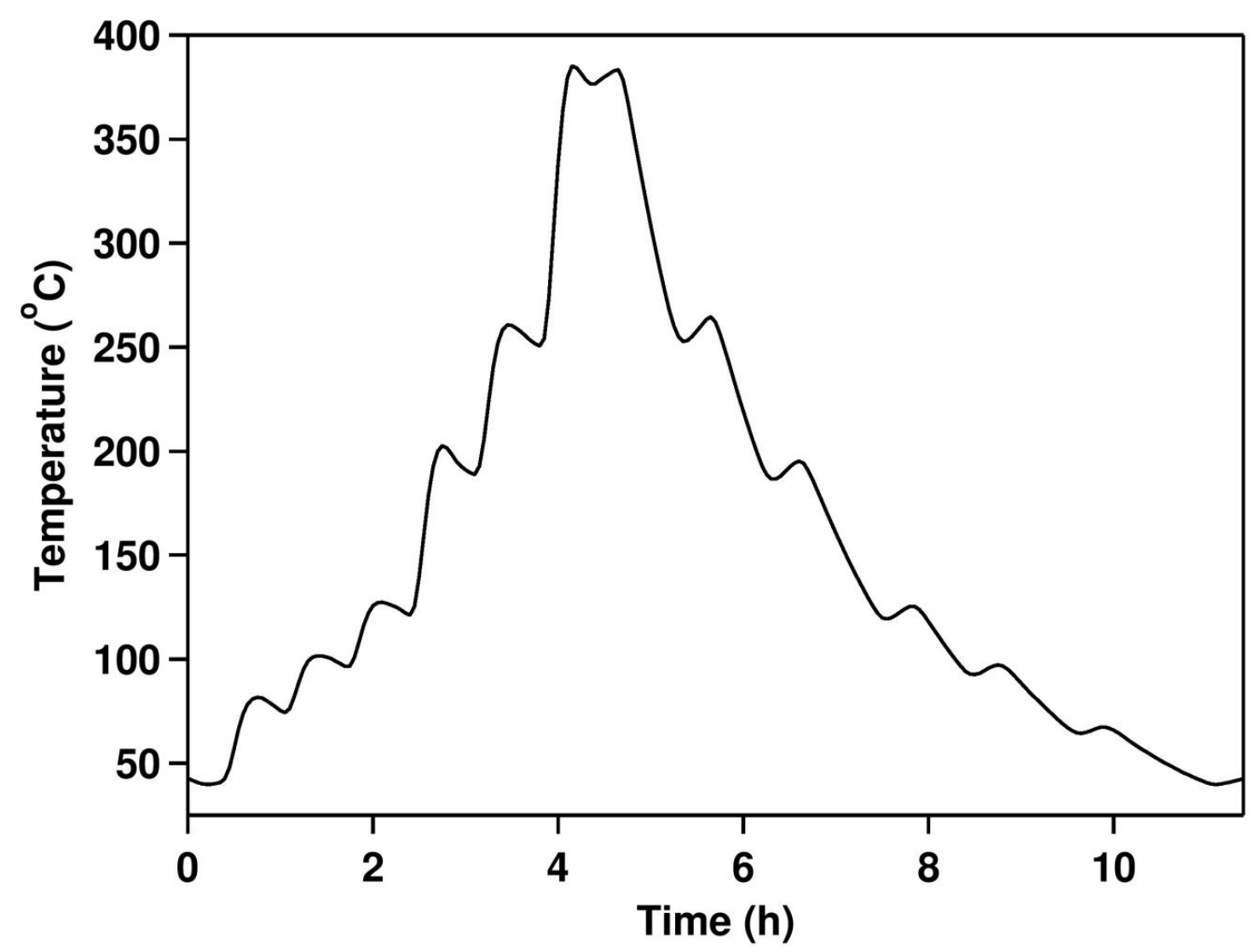

Figure S4: Temperature profile of a TD cycle during the campaign. 

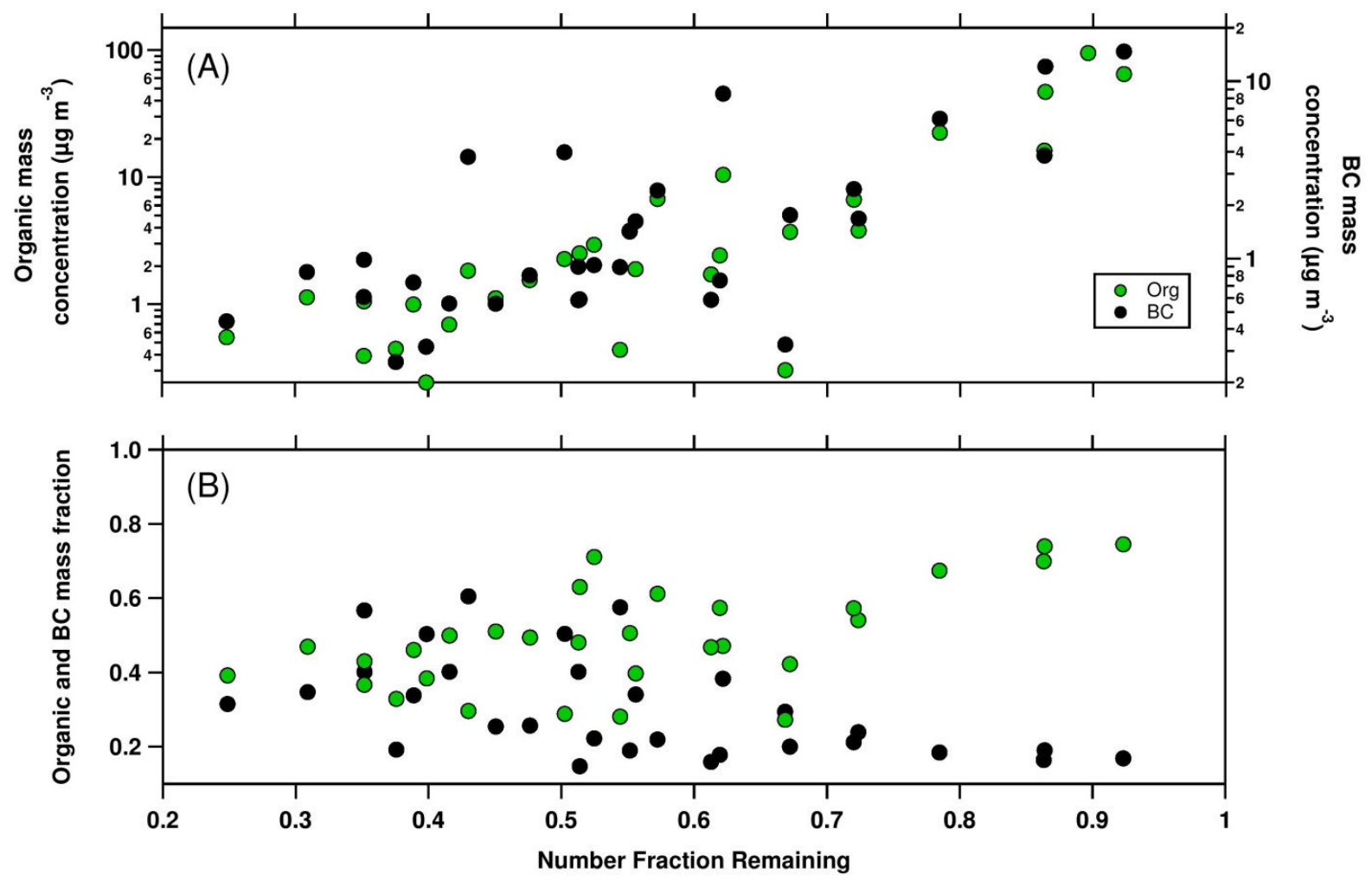

Figure S5: The number fraction remaining during the Athens 2013 winter campaign as a function of (A) the organic (green) and BC (black) average mass concentration in logarithmic scale, and (B) the organic (green) and BC (black) mass fraction remaining.

BC concentration correlated well with the NFR during the Athens 2013 winter campaign (Fig. 4). This was not the case for the $\mathrm{BC}$ mass fraction because of the existence of the nighttime periods with a lot of biomass burning organic aerosol and the rush hour morning periods with a lot of aerosol from traffic. During the traffic-dominated periods there were relatively high BC mass fractions but relatively low NFRs because of the existence of small semi-volatile particles in the traffic emissions. During the nighttime biomass burning periods the mass fraction of $\mathrm{BC}$ was lower because there were a lot of organic compounds emitted from this source. However, because most particles include an extremely low volatility core these low BC mass fractions correspond to higher NFRs. 


\subsection{Biomass burning periods}

Table S1: Average contribution of the different pollution sources for the four representative biomass burning periods, for ambient measurements (BP) and after $400{ }^{\circ} \mathrm{C}$ (TD), based on the PMF analysis. The $\%$ mass fraction remaining after $400{ }^{\circ} \mathrm{C}$ is also given.

\begin{tabular}{ccccc}
\hline & \multicolumn{4}{c}{ Mass Concentration (\% of OA) } \\
\cline { 2 - 5 } Mode* & BBOA & HOA & OOA & COA \\
\hline BP & $23(76 \%)$ & $1.5(5 \%)$ & $2.4(8 \%)$ & $3(10 \%)$ \\
TD & $2.1(47 \%)$ & $0.5(10 \%)$ & $1.8(40 \%)$ & $0.1(3 \%)$ \\
\hline Mass fraction remaining (\%) & 9 & 33 & 75 & 3 \\
\hline *BP and TD results
\end{tabular}

*BP and TD results have a $13 \%$ and $20 \%$ unexplained organic mass from the PMF analysis, respectively.

Table S2: Average mass concentration of the major species (in ) for the biomass burning periods, given for both modes (BP for ambient conditions and TD after $400{ }^{\circ} \mathrm{C}$ ), during the Athens 2013 campaign. Number fraction remaining (NFR) for each event and the average mass fraction remaining of each species are also provided.

\begin{tabular}{|c|c|c|c|c|c|c|c|}
\hline \multirow[b]{2}{*}{ Date } & \multirow[b]{2}{*}{ Mode } & \multicolumn{6}{|c|}{ Mass Concentration (in ) (Percentage of $\left.\mathrm{PM}_{1}\right)$} \\
\hline & & Organics & Sulfate & Nitrate & Ammonium & $\mathrm{BC}^{\mathrm{a}}$ & NFR \\
\hline \multirow{2}{*}{$\begin{array}{c}1 . \\
(13 \operatorname{Jan} 2013 \text { 03:45) }\end{array}$} & $\mathrm{BP}$ & $47(1.1 \%)$ & $1.1(2 \%)$ & $1.8(3 \%)$ & $0.8(1 \%)$ & $12(19 \%)$ & \multirow{2}{*}{0.86} \\
\hline & TD & $9(42 \%)$ & $0.3(1 \%)$ & $0.2(1 \%)$ & $0.05(<1 \%)$ & $12(56 \%)$ & \\
\hline \multirow{2}{*}{$\begin{array}{c}2 . \\
\text { (13 Jan 2013 22:45) }\end{array}$} & $\mathrm{BP}$ & $65(76 \%)$ & $2.4(3 \%)$ & $2.1(2 \%)$ & $1.5(2 \%)$ & $14.7(17 \%)$ & \multirow{2}{*}{0.92} \\
\hline & TD & $11(41 \%)$ & $0.7(3 \%)$ & $0.3(1 \%)$ & $0.2(<1 \%)$ & $14.7(55 \%)$ & \\
\hline \multirow{2}{*}{$\begin{array}{c}3 . \\
(14 \operatorname{Jan} 2013 \text { 23:05) }\end{array}$} & $\mathrm{BP}$ & $6.7(62 \%)$ & $0.7(6 \%)$ & $0.5(5 \%)$ & $0.45(4 \%)$ & $2.4(23 \%)$ & \multirow{2}{*}{0.57} \\
\hline & TD & $1.2(31 \%)$ & $0.2(4 \%)$ & $0.09(2 \%)$ & $0.05(1 \%)$ & $2.4(62 \%)$ & \\
\hline \multirow{4}{*}{$\begin{array}{c}4 . \\
(24 \operatorname{Jan} 2013 \text { 04:15) }\end{array}$} & $\mathrm{BP}$ & $16.2(71 \%)$ & $1.2(5 \%)$ & $1.0(4 \%)$ & $0.6(2 \%)$ & $4(18 \%)$ & \multirow{2}{*}{0.86} \\
\hline & TD & $2(32 \%)$ & $0.2(3 \%)$ & $0.13(2 \%)$ & $0.04(<1 \%)$ & $4(62 \%)$ & \\
\hline & & \multicolumn{6}{|c|}{ Average mass fraction remaining $(\%)$ at $400^{\circ} \mathrm{C}$} \\
\hline & & 17 & 25 & 13 & 9 & 100 & 80 \\
\hline
\end{tabular}




\subsection{Traffic periods}

Table S3: Average contribution of the different pollution sources for the three representative traffic periods, for ambient measurements (BP) and after $400{ }^{\circ} \mathrm{C}$ (TD), estimated by PMF analysis. The $\%$ mass fraction remaining after $400{ }^{\circ} \mathrm{C}$ is also given.

\begin{tabular}{ccccc}
\hline & \multicolumn{3}{c}{ Mass Concentration ()(\% of OA) } \\
\cline { 2 - 5 } Mode* & BBOA & HOA & OOA & COA \\
\hline BP & $0.5(11 \%)$ & $3(70 \%)$ & $0.5(12 \%)$ & $0.3(6 \%)$ \\
TD & $0.2(2 \%)$ & $0.6(57 \%)$ & $0.4(38 \%)$ & $0.03(3 \%)$ \\
\hline Mass fraction remaining (\%) & 40 & 20 & 76 & 10 \\
\hline
\end{tabular}

*BP and TD results have a $12 \%$ and $24 \%$ unexplained organic mass from the PMF analysis, respectively.

Table S4: Average mass concentration of the major species (in ) for the representative traffic periods, given for both modes (BP for ambient conditions and TD after $400{ }^{\circ} \mathrm{C}$ ), during the Athens 2013 campaign. The number fraction remaining (NFR) for each event and the average mass fraction remaining of each species and NFR is also provided.

\begin{tabular}{|c|c|c|c|c|c|c|c|}
\hline \multirow[b]{2}{*}{ Date } & \multirow[b]{2}{*}{ Mode } & \multicolumn{6}{|c|}{ Mass Concentration (in ) (Percentage if $\left.\mathrm{PM}_{1}\right)$} \\
\hline & & Organics & Sulfate & Nitrate & Ammonium & $\mathrm{BC}^{\mathrm{a}}$ & NFR \\
\hline \multirow{2}{*}{$\begin{array}{c}1 . \\
(14 \operatorname{Jan} 2013 \text { 09:10) }\end{array}$} & $\mathrm{BP}$ & $10.5(48 \%)$ & $1.1(5 \%)$ & $1.2(5 \%)$ & $0.65(3 \%)$ & $8.5(39 \%)$ & \multirow{2}{*}{0.62} \\
\hline & TD & $2.5(2 \%)$ & $0.2(2 \%)$ & $0.2(2 \%)$ & $0.08(<1 \%)$ & $8.5(74 \%)$ & \\
\hline \multirow{2}{*}{$\begin{array}{c}2 . \\
(15 \operatorname{Jan} 201308: 40)\end{array}$} & BP & $2.3(29 \%)$ & $0.7(9 \%)$ & $0.5(6 \%)$ & $0.4(5 \%)$ & $4(51 \%)$ & \multirow{2}{*}{0.5} \\
\hline & TD & $0.8(16 \%)$ & $0.13(2 \%)$ & $0.1(2 \%)$ & $0.05(<1 \%)$ & $4(79 \%)$ & \\
\hline \multirow{4}{*}{$\begin{array}{c}3 . \\
(17 \operatorname{Jan} 201307: 20)\end{array}$} & BP & $1.8(30 \%)$ & $0.3(5 \%)$ & $0.2(3 \%)$ & $0.1(1 \%)$ & $3.7(61 \%)$ & \multirow{2}{*}{0.43} \\
\hline & TD & $0.5(11 \%)$ & $0.07(2 \%)$ & $0.05(1 \%)$ & $0.01(<1 \%)$ & $3.7(86 \%)$ & \\
\hline & & \multicolumn{6}{|c|}{ Average mass fraction remaining $(\%)$ at $400{ }^{\circ} \mathrm{C}$} \\
\hline & & 26 & 19 & 18 & 12 & 100 & 52 \\
\hline
\end{tabular}




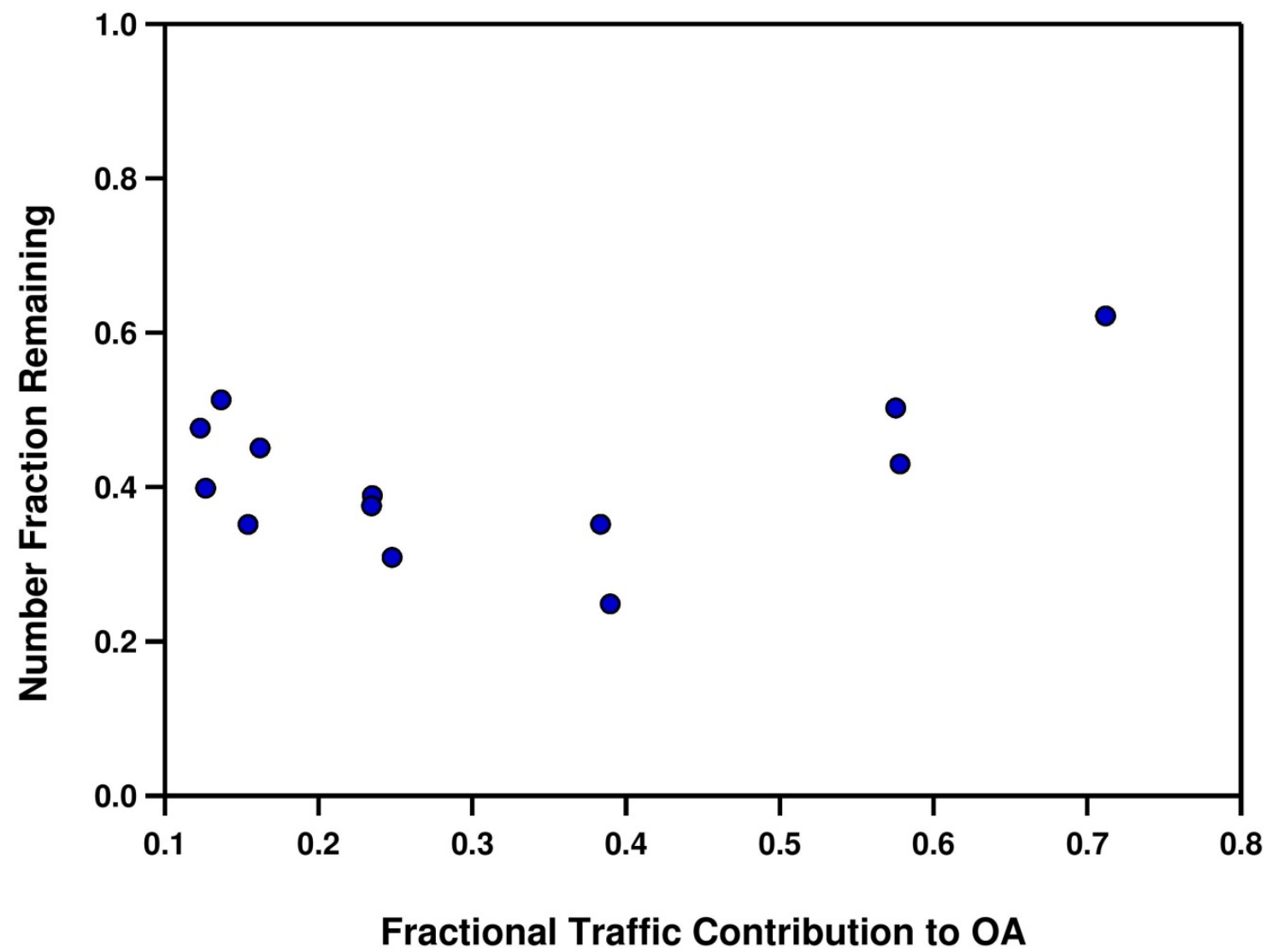

Figure S6: The number fraction remaining as a function of the fractional contribution of traffic to the organic aerosol mass. Each point corresponds to 0.5-1.2 hours. 